\title{
Measurement of Alcohol Use and Misuse in a Cohort of Students Followed from Grade 6 Through Grade 12
}

\author{
Jean T. Shope, Laurel A. Copeland, and T.E. Dielman
}

\begin{abstract}
In following a cohort of students from grade 6 through grade 12 for the purpose of evaluating an Alcohol Misuse Prevention Study curriculum, a substudy of the measurement of alcohol use and misuse was conducted. The 6-year follow-up of young people over time afforded a good opportunity to assess the adequacy of the initially chosen measures to 1) provide data with statistically desirable properties, and 2) be sensitive to and representative of the wide range of alcohol use and misuse patterns among adolescents as they mature. Revised measures of alcohol use and misuse were developed from the data responding to the same questionnaire items that had been used throughout the study. The revised measures demonstrated good psychometric properties and may be useful in other studies.
\end{abstract}

Key Words: Adolescents, Alcohol Use, Alcohol Misuse, Measurement, Longitudinal Cohort.

$\mathbf{T}$ HE CONCEPTUALIZATION and measurement of alcohol use and misuse have received attention from numerous investigators, ${ }^{1-5}$ but primarily with a focus on studies of adults. Adolescent alcohol use and misuse must also be assessed by careful measurement in the several different types of studies likely to be conducted: those that assess prevalence, changing trends, antecedents, and the effectiveness of alcohol use/misuse prevention interventions. Replicability of the measures is important, so that comparisons among studies can be made. In selecting measures for research with young people, investigators should consider the measures' appropriateness for the age group being studied. Alcohol use changes dramatically from elementary school through high school, thus item wording and sensitivity of the measures must be carefully evaluated. Although different measures may be appropriate for different ages, in longitudinal studies, utilization of the same questionnaire items over time and of measures that are sensitive to change is critical.

In 1984 when the authors began the study reported herein, there were few sources of information on alcohol

From the University of Michigan Transportation Research Institute (J.T.S., L.A.C.); Department of Postgraduate Medicine and Health Professions Education, University of Michigan Medical School (T.E.D.); and Department of Health Behavior and Health Education, University of Michigan School of Public Health (J.T.S., T.E.D.), Ann Arbor, Michigan.

Received for publication March 17, 1993; accepted November 16, 1993

This study was supported by the National Institute on Alcohol Abuse and Alcoholism, Grants AA 06324 and AA 09026

Reprint requests: Jean T. Shope, Ph.D., University of Michigan Transportation Research Institute, 2901 Baxter Road, Ann Arbor, MI 48109. 2150.

Copyright $₫ 1994$ by The Research Society on Alcoholism. use and misuse measures utilized by other researchers with adolescents. Researchers who had worked with large samples of adolescents included primarily Jessor et al.,6,7 Greenwald, ${ }^{8}$ Rachal et al., ${ }^{9}$ and Bachman et al. ${ }^{10}$ The measures of Jessor and Jessor's group ${ }^{6}$ had been adapted and revised by Rachal et al. ${ }^{9}$ Bachman et al.'s ${ }^{10}$ Monitoring the Future Project at that time surveyed only high school seniors and older respondents, so their items contained higher reading levels in a more complex format, and used a shorter time frame (past 2 weeks) than would be appropriate for the younger students who were the focus of the current study. Questionnaire items for younger students should use developmentally appropriate reading levels, a simple format, and a time frame for alcohol use that is likely to result in a reasonable proportion of positive responses. Very few elementary students would report alcohol use in the past 2 weeks. In addition, the Monitoring the Future items ${ }^{10}$ asked about "a drink of alcohol," and did not specify types of beverages (e.g., beer, wine, or liquor) that would be clearer to younger students with less cognitive ability and therefore result in more valid data. Only Jessor and Jessor ${ }^{6}$ measured alcohol use among students in grades as low as 7,8, and 9. Their focus, however, was on the onset of drinking, not the frequency and quantity or the consequences of drinking as needed in the current study. The measures from Greenwald, ${ }^{8}$ and Rachal et al., ${ }^{9}$ although targeted toward older students, were more appropriate for adaptation for the study reported herein. Their questionnaire items covered the dimensions being studied and were amenable to adaptation for the reading levels of the upper elementary students targeted in this study.

More recently, several other researchers have reported on alcohol use and misuse among younger adolescents, primarily middle school age, in the context of reporting prevention intervention results. ${ }^{11-14}$ Differing measures, item-wordings, and levels of specificity were utilized. In addition, time frames varied or several were used. Measures were constructed differently from the items, often resulting in dichotomous variables. The current study required interval level data for the planned repeated measures analyses of variance.

In the context of evaluating the curriculum used in the Alcohol Misuse Prevention Study (AMPS), questionnaire items were selected, adapted, and refined as detailed, with summary measures created from responses to those items. 
Utilization of essentially the same alcohol frequency/ quantity and misuse questionnaire items over time allowed the authors to assess how adequately the constructed indices measured alcohol use and misuse as the adolescent subjects progressed from $\sim 12-18$ years of age. The purpose of this report is to describe the specific questionnaire items used in the study, the responses obtained from the same students at four different points in time, the initial measures developed from responses to those items, and the revised measures. Knowledge gained through the refinement of the measures in this study should be helpful to others who wish to assess alcohol use and misuse among young people making the transition from childhood to adulthood.

\section{METHODS}

\section{Setting/Subjects}

From 1984 through 1991, six school districts in southeastern Michigan participated in AMPS, allowing project staff to administer questionnaires to students with parental permission and to teach the AMPS curriculum to a portion of their students in 6th and 10th grades, the other portion serving as controls. ${ }^{15,16}$ Data collection began when the students included in this report were in 6th grade and continued through their 12th grade year. Only half the students were pretested to study the effects of pretesting. ${ }^{17}$ Therefore, to maximize the size of the longitudinal sample for this report, data collection occasions in the second terms of the 6th, 8 th, 10th, and 12th grades (posttests 1, 3, 5, and 6) were used. This selection of survey occasions also provided data on students' alcohol use and misuse at relatively equal time intervals. Data obtained from all students, both experimental and control, are included in this report on the measures utilized. The effectiveness of the curriculum was reported elsewhere. ${ }^{18,19}$

Unfortunately, one district's consent procedures changed from passive to active during the high school years of the study and many students from that district were lost to follow-up. Although formerly that district comprised $20 \%$ of the composite sample, by the last survey occasion, that district comprised only $7 \%$ of the sample. In addition, students from that district who continued in the study after the change had reported significantly different alcohol use and misuse responses at the 10th grade data collection occasion from those who stopped participating. Because the participating 12th grade students were not representative of the district, data from that district at all four survey occasions were removed from the data set used in this report.

Students completed questionnaires that covered several psychosocial topics, as well as self-reported alcohol use and misuse. Trained project staff administered the questionnaires in students' regular classrooms and answered students' questions in a standardized manner. Students were assured that their responses would be confidential, and classroom teachers were asked to position themselves so as not to inhibit or bias the students' responses. Of a total of 2301 eligible 6 th grade students (from the five usable districts), 2088 ( $90.7 \%$ ) completed questionnaires in the spring of 1985. Parents denied participation permission for 24 students, and 189 were absent at the time of the questionnaire administration. The sample was comprised of $52.0 \%$ boys and $48.0 \%$ girls. Self-reported ethnicity of the students was as follows: $82.0 \%$ White, $13.7 \%$ Black, and $4.3 \%$ other, with six cases not reported. At subsequent data collection occasions, data were collected from the original cohort as follows: 1476 $(70.7 \%)$ in 8 th grade, $970(46.5 \%)$ in 10th grade, and $613(29.4 \%)$ in 12 th grade. Absenteeism at any single survey occasion was the primary cause of loss of subjects to the longitudinal sample. The study did not administer follow-up surveys to absentees. Family moves out of the area occurred at a rate of $\sim 10 \%$ year.

Of the 613 students who completed questionnaires at all four survey occasions, $49.8 \%$ were boys and $50.2 \%$ were girls. Self-reported ethnicity of these students was as follows: $85.8 \%$ White, $10.8 \%$ Black, and $3.4 \%$ other, with one case not reported. $\chi^{2}$ analyses revealed that the longitudinal group of students was not significantly different from the original cohort in sex distribution, but was significantly different in racial composition. Attrition in the categories "Black" and "other" was higher than in the category "White" $(p=0.01)$. Student's $t$ tests on two alcohol measures also revealed that the longitudinal cohort reported significantly less alcohol use and alcohol misuse in 6th grade than did the students who were unavailable to longitudinal follow-up [mean (SD) on scales of $0-6$ for use $=0.33(0.66)$ vs. $0.51(1.04)$; and of $0-10$ for misuse $=0.45$ (0.99) vs. $0.81(1.47) ; p=0.00]$

\section{Measures and Analyses}

Validity. Students self-reported their alcohol use and misuse. Concerns regarding the validity of adolescents' self-reports of alcohol use, an undesirable behavior, were examined during pilot testing of the questionnaire, using a "bogus pipeline" technique designed to assess students' differential reporting on 11 variables when faced with the prospect of independent biochemical verification of their self-reports. The bogus pipeline procedure did not affect alcohol use and misuse reports compared with the control group's reports. These results, ${ }^{20}$ together with other evidence that students' self-reports of substance use are at least as valid with assurance of confidentiality as with utilization of the bogus pipeline procedure, ${ }^{21-23}$ led to the conclusion that such a procedure was unnecessary in the study's main data collection.

Alcohol Use. Alcohol use was assessed by several different items, the wording of which was refined during pilot testing of the questionnaire. ${ }^{\text {is }}$ To assess alcohol use in general, students were asked about whether they had ever used alcohol and about use in the past 12 months, as well as in the past month (see Table 1 for item wording). In addition, when the students reached high school, two items concerning having had five or more drinks in a row (Table 1) were added to the questionnaire.

To assess frequency and quantity of alcohol use, separate items for beer, wine, and liquor were written, adapted by study staff from the work of Rachal et al. ${ }^{9}$ Separate frequency of alcohol use questions were asked for each substance: How often have you had beer (wine. liquor) in the past 12 months? Responses to and codes for the frequency items were: never (0), a few times a year or less (1), about once a month (2), about once a week (3), 3 or 4 days a week (4), and every day (5). Quantity was also assessed separately for each substance: When you drank beer (wine, liquor) during the past 12 months, how many cans/bottles (glasses, drinks) did you usually have at one time? Responses to and codes for the quantity items were: none (0), <1 drink (1), 1 drink (2), 2 drinks (3), 3 or 4 drinks (4), 5 or 6 drinks (5), and 7 or more drinks (6). The questionnaire used through grade 8 contained the additional response, "I've only had a taste," for the frequency and quantity questions, but that response was difficult to interpret-was a taste a small portion of a whole drink? If so, what portion? Some tasters perceived themselves as nondrinkers, commenting on the questionnaire, "But, I don't drink." Were all tasters really nondrinkers? Because of these uncertainties, the taste-only response choice was dropped from the questionnaire when refinements were made in the item wordings for grades 10 and 12 . In reported results, the "tasters" were included in the "none" category for each substance, because they typically reported tasting on only one occasion. An alcohol frequency/quantity index for each student at each data collection point was created by multiplying frequency times quantity for each of the three substances, recoding the data as drinks/week, then adding the three substances to yield the total number of drinks/week. This variable (number of drinks/week) was then collapsed to form a 7-point scale reflecting no drinking (0) to 10 or more drinks/week (6), as shown under "initial measure" in Table 2.

When the students' 10 th and 12 th grade data were being analyzed, it became apparent that the frequency/quantity categories established previously from the continuous drinks/week variable could be improved on. Even at older ages and with increased drinking levels, the measure 
Table 1. Percentage of Student Cohort $(n=613)$ Reporting Each Response to General Alcohol Use Items Over Time

\begin{tabular}{|c|c|c|c|c|c|}
\hline Items & Responses & Grade 6 & Grade 8 & Grade 10 & Grade 12 \\
\hline \multirow{2}{*}{$\begin{array}{l}\text { 1. Did you ever drink any beer, wine, hard liquor, or other } \\
\text { drink with alcohol in it? }\end{array}$} & No & 70.3 & 37.5 & 12.2 & 6.2 \\
\hline & Yes & 29.7 & 62.5 & 87.8 & 93.8 \\
\hline \multirow{2}{*}{$\begin{array}{l}\text { 2. Did you drink any beer, wine, hard liquor, or other drink } \\
\text { with alcohol in it in the past } 12 \text { months? }\end{array}$} & No & 70.7 & 45.2 & 28.8 & 20.8 \\
\hline & Yes & 29.3 & 54.8 & 71.2 & 79.2 \\
\hline \multirow{2}{*}{$\begin{array}{l}\text { 3. Did you drink any beer, wine, hard liquor, or other drink } \\
\text { with alcohol in it in the past month? }\end{array}$} & No & 92.4 & 75.2 & 58.0 & 45.5 \\
\hline & Yes & 7.6 & 24.8 & 42.0 & 54.5 \\
\hline \multirow{6}{*}{$\begin{array}{l}\text { 4. During the past } 12 \text { months, how many times have you } \\
\text { had } 5 \text { or more drinks in a row? }\end{array}$} & None & $\mathrm{NA}^{*}$ & NA & 58.2 & 43.2 \\
\hline & Once & & & 12.9 & 10.1 \\
\hline & Twice & & & 8.2 & 8.3 \\
\hline & 3-5 times & & & 8.5 & 15.3 \\
\hline & $6-9$ times & & & 4.4 & 7.6 \\
\hline & $10+$ times & & & 7.8 & 15.5 \\
\hline \multirow{6}{*}{$\begin{array}{l}\text { 5. During the past month, how many times have you had } 5 \\
\text { or more drinks in a row? }\end{array}$} & None & NA & NA & 76.6 & 66.0 \\
\hline & Once & & & 10.8 & 11.7 \\
\hline & Twice & & & 5.4 & 7.2 \\
\hline & 3-5 times & & & 4.4 & 7.5 \\
\hline & $6-9$ times & & & 1.0 & 2.2 \\
\hline & $10+$ times & & & 1.7 & 5.4 \\
\hline
\end{tabular}

Note: Missing data not included in percentages (6th, $n=11-46 ; 8$ th, $n=26-35 ; 10$ th, $n=0-39 ; 12$ th, $n=0-41$ ).

- NA, not applicable. Item was not asked of students in grades 6 and 8.

Table 2. Percentage of Student Cohort ( $n=613$ ) Reporting Each Category of Alcohol Frequency/Quantity for the Previous Year (Initial and Revised Measures) by Grade Over Time*

\begin{tabular}{lcccc}
\multicolumn{1}{c}{ No. of drinks } & Grade 6 & Grade 8 & Grade 10 & Grade 12 \\
\hline & \multicolumn{5}{c}{ Initial Measure } \\
0) None & 72.5 & 47.1 & 29.4 & 21.5 \\
1) $<1 /$ week & 24.7 & 43.0 & 44.3 & 38.5 \\
2) 1 to <2/week & 1.7 & 3.4 & 6.8 & 9.3 \\
3) 2 to <4/week & 0.2 & 2.9 & 7.5 & 6.6 \\
4) 4 to <6/week & 0.3 & 1.2 & 2.1 & 5.3 \\
5) 6 to <10/week & 0.5 & 1.0 & 5.1 & 9.3 \\
6) 10 or more/week & 0.2 & 1.5 & 4.9 & 9.6 \\
Mean & 0.33 & 0.77 & 1.43 & 2.02 \\
so & 0.68 & 1.10 & 1.64 & 1.97 \\
Coefficient of skewness & 3.69 & 2.62 & 1.52 & 0.89 \\
& & & & \\
& & Revised & Measure & \\
0) None & 72.5 & 47.1 & 29.4 & 21.5 \\
1) <1/month & 18.2 & 24.3 & 24.9 & 16.4 \\
2) 1 to <2/month & 4.8 & 10.2 & 9.8 & 10.1 \\
3) 2 to <4/month & 1.7 & 8.4 & 9.6 & 12.1 \\
4) 1 to <3/week & 1.8 & 5.2 & 11.5 & 12.9 \\
5) 3 to <8/week & 0.7 & 2.7 & 9.1 & 14.0 \\
6) 8 or more/week & 0.3 & 2.0 & 5.7 & 13.1 \\
Mean & 0.46 & 1.16 & 2.00 & 2.73 \\
so & 0.95 & 1.51 & 1.93 & 2.12 \\
Coefficient of skewness & 2.86 & 1.40 & 0.65 & 0.13 \\
\hline
\end{tabular}

* Missing data not included in percentages (6th, $n=13 ; 8$ th, $n=17 ; 10$ th, $n=$ 39; 12 th, $n=8$ ).

was still highly skewed, because the majority of students' responses fell into two categories: none and $<1 \mathrm{drink} /$ week. It was desirable to select categories that would represent the full range of data well and provide a reasonably even distribution of data across categories to facilitate analyses requiring interval level data. Several categorization schemes were tried with the continuous variable of total number of drinks/week. Ultimately, seven revised categories were chosen that were meaningful in terms of number of drinks/week and also resulted in a nearly rectangular distribution, at least at the high school grade levels (see categories under "revised measure" in Table 2).

Alcohol Misuse. Alcohol misuse was measured by 10 items adapted by study staff from the work of Greenwald ${ }^{8}$ and Rachal et al. ${ }^{9}$ The alcohol misuse items assessed the frequency of various types of negative consequences experienced as a result of alcohol misuse during the previous 12 months (see Table 3 for item wording). Because of the low frequency of misuse reported at early data collection points, student responses to each item were initially collapsed to none $(0)$ and at least once (1). In early reports, ${ }^{15-17,24}$ these items were summarized into three indices that were constructed a priori on a face validity basis (Table 3). The indices were "overindulgence," "trouble with peers," and "trouble with adults." $\alpha$-Coefficients, calculated on the pretested 5th and 6th grade students $(n=2589)$ for the separate misuse indices were $0.63,0.66$, and 0.21 , respectively, as reported elsewhere. ${ }^{24}$ In later reports, ${ }^{18,19}$ these collapsed scores were then summed to create an overall index of total alcohol misuse, reflecting the sum of a students' experience with several different types of negative consequences of alcohol misuse (Table 3).

Although the indices used initially and reported in Table 3 were useful when the students were young, they did not reveal as much information as they could have about the older students' responses. By the 12th grade, more students reported experiencing a given type of negative drinking consequence two or more times. A student who has experienced a negative consequence only once may be different from a student who has repeatedly experienced such a consequence. Collapsing each item into a dichotomous variable ignored this aspect of the data. It was decided therefore to revise the measures of misuse to incorporate the repeated negative consequences evidenced by more students when they reached higher grades. In addition, treating all types of consequences of drinking as being of equal severity by summing experience with all types of misuse was called into question. The initially used alcohol misuse measures had been created a priori. With the higher grade levels reporting more misuse, it became possible to factor analyze response data on the items and to create indices with known psychometric properties.

Matrices of Pearson product moment correlations among all the alcohol misuse items were first subjected to a principal components analysis. Kaiser's criterion of lambda $\geq 1.0$ was used to determine the number of factors extracted. The communality estimates were initialized to unity and ended when there were no changes in the third decimal place. Subsequent principal axes solutions were rotated to both orthogonal (Varimax) and oblique (Oblimin) criteria. The primary factor intercorrelations were on the order of 0.40 . Factor loadings were virtually identical for the two solutions, so the uncorrelated solution was used. Varimax solutions were obtained, using data collected from 3110 students in the fall of their 10th grade year, and replicated on data collected from 2965 students later in the 10th grade year, and from 1437 students in the winter of their 12 th grade year. The principal components analysis of the correlation matrices resulted in three eigenvalues $\geq 1.0$. Items, factor loadings, indices, and $\alpha$-levels from the 10th grade and 12 th grade analyses are reported in Table 4 . All three analyses produced similar loadings. $\alpha$-Coefficients calculated for indices built on these factors were 
Table 3. Alcohol Misuse Items for the Previous Year, initial Indices, Codes, and Percentage of Student Cohort in Each Response Category Dy Grade Over Time

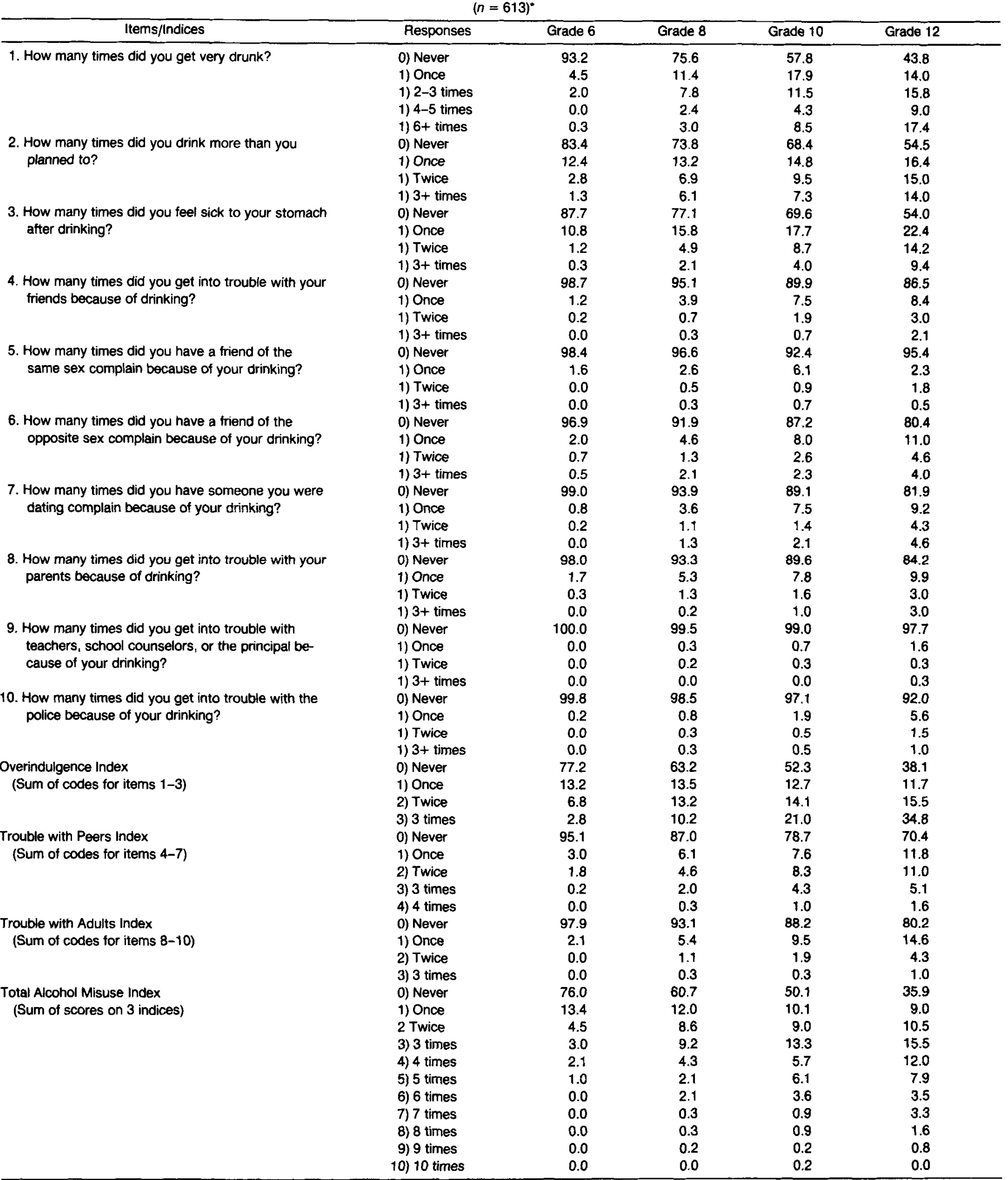

Missing data not included in percentages (items: 6 th, $n=6-10 ; 8$ th, $n=3-7 ; 10$ th, $n=35-37,12$ th, $n=3-7$. Indices: 6 th, $n=8$; 8 th, $n=6-8$; 10th, $n=35-37$; 12th, $n=3-6$ ). 
Table 4. $\alpha$-Coefficients and Factor Loadings on Revised Alcohol Misuse Items for All Grade 10 and Grade 12 Students*

\begin{tabular}{|c|c|c|c|c|c|c|c|c|c|}
\hline \multirow[b]{2}{*}{ Factor/item } & \multicolumn{3}{|c|}{ Factor 1} & \multicolumn{3}{|c|}{ Factor 2} & \multicolumn{3}{|c|}{ Factor 3} \\
\hline & Early grade & $\begin{array}{l}\text { Late grade } \\
10\end{array}$ & $\begin{array}{l}\text { Late grade } \\
12\end{array}$ & ${ }_{10}$ Early grade & $\begin{array}{c}\text { Late grade } \\
10\end{array}$ & Late grade & ${ }_{10}^{\text {Early grade }}$ & $\begin{array}{l}\text { Late grade } \\
10\end{array}$ & $\begin{array}{l}\text { Late grade } \\
12\end{array}$ \\
\hline Overindulgence $(\alpha)$ & $(0.75)$ & $(0.77)$ & $(0.78)$ & & & & & & \\
\hline Drink more than planned, $2 \dagger$ & 0.81 & 0.83 & 0.79 & 0.15 & 0.14 & 0.18 & 0.13 & 0.12 & 0.12 \\
\hline Very drunk, 1 & 0.78 & 0.78 & 0.79 & 0.19 & 0.20 & 0.22 & 0.21 & 0.19 & 0.14 \\
\hline Sick after drinking, 3 & 0.78 & 0.78 & 0.83 & 0.13 & 0.12 & 0.06 & 0.09 & 0.13 & 0.09 \\
\hline Complaints $(\alpha)$ & & & & $(0.73)$ & $(0.74)$ & $(0.72)$ & & & \\
\hline Opposite sex friend, 6 & 0.17 & 0.17 & 0.16 & 0.89 & 0.89 & 0.88 & 0.10 & 0.13 & 0.03 \\
\hline Date, 7 & 0.16 & 0.12 & 0.13 & 0.85 & 0.89 & 0.86 & 0.08 & 0.10 & 0.06 \\
\hline Same sex friend, 5 & 0.12 & 0.20 & 0.11 & 0.57 & 0.51 & 0.52 & 0.23 & 0.30 & 0.16 \\
\hline Trouble $(\alpha)$ & & & & & & & $(0.64)$ & $(0.67)$ & $(0.63)$ \\
\hline School, 9 & -0.04 & -0.05 & -0.04 & 0.00 & 0.16 & -0.07 & 0.74 & 0.73 & 0.77 \\
\hline Police, 10 & 0.13 & 0.12 & 0.12 & 0.17 & 0.07 & 0.21 & 0.69 & 0.72 & 0.70 \\
\hline Parents, 8 & 0.34 & 0.35 & 0.38 & 0.16 & 0.11 & 0.16 & 0.61 & 0.66 & 0.59 \\
\hline Friends, 4 & 0.31 & 0.34 & 0.32 & 0.28 & 0.24 & 0.40 & 0.59 & 0.60 & 0.50 \\
\hline
\end{tabular}

"Early grade 10, $n=3110$; late grade 10, $n=2965$; late grade 12, $n=1866$.

† Item number and content from Table 3.

substantially higher $(0.63-0.78)$ than those of the initial misuse indices $(0.21-0.63)$ described herein.

Indices for the revised measures were built according to the factors identified, including each variable in only the index for which the variable had the highest factor loading and using the full distribution of scores for each negative consequence. Valid responses were summed to produce each index. Respondents with valid responses on fewer than half the items were assigned missing data codes on the indices. Codes for the revised indices are reported in Table 5. Because skewness on two of the indices, Trouble and Complaints, was $>2.0$, these indices were collapsed for analytic purposes. Although skewness is still somewhat evident with the Trouble index, for consistency with the Complaints index, five coded categories were retained: never, once, twice, three to four times, and five or more times.

Additional data analyses for this report included frequency distributions, and Pearson product moment correlations that were computed among the revised alcohol misuse indices and the frequency/quantity index of alcohol use.

\section{RESULTS}

\section{Alcohol Use}

The percentages of the cohort at each grade level over time responding to items regarding ever having drunk alcohol, alcohol use in the past 12 months, and use in the past month are presented in Table 1. Table 1 also shows the percentages of students responding to the items reflecting 5 or more drinks in a row. The percentages of students responding "no" or "none" consistently decreased over time, as the percentages reporting "yes" and having had 5 or more drinks in a row consistently increased.

Figure 1 shows the increasing use over time for beer, liquor, and wine separately, with 12th grade students (including nondrinkers) reporting averages of two and one half (2.46) cans or bottles of beer, nearly a whole drink $(0.94)$ of liquor, and half glass $(0.49)$ of wine/week. The overall alcohol use measure (the frequency/quantity index built from the beer, liquor, and wine data) results are reported in Table 2 in the "initial measure" section, with percentages of students reporting each of the initial seven categories of drinks. The decrease in percentages of stu-
Table 5. Percentage of Student Cohort ( $n=613$ ) Reporting Each Frequency on Revised Alcohol Misuse Indices by Grade Over Time*

\begin{tabular}{|c|c|c|c|c|}
\hline $\begin{array}{l}\text { Codes/responses for each } \\
\text { index }\end{array}$ & Grade 6 & Grade 8 & Grade 10 & Grade 12 \\
\hline \multicolumn{5}{|l|}{ Overindulgence† } \\
\hline 0) Never & 77.2 & 63.2 & 52.3 & 38.1 \\
\hline 1) Once & 11.4 & 9.5 & 8.2 & 7.2 \\
\hline 2) Twice & 5.1 & 7.9 & 8.5 & 5.8 \\
\hline 3) 3 times & 3.1 & 4.8 & 8.0 & 7.7 \\
\hline 4) 4 times & 2.0 & 3.5 & 5.6 & 8.6 \\
\hline 5) 5 times & 0.5 & 3.9 & 4.5 & 6.1 \\
\hline 6) 6 times & 0.3 & 1.3 & 4.9 & 7.9 \\
\hline 7) 7 times & 0.0 & 1.0 & 2.8 & 5.8 \\
\hline 8) 8 times & 0.0 & 1.2 & 2.3 & 5.6 \\
\hline 9) 9 times & 0.2 & 1.5 & 1.6 & 3.1 \\
\hline 10) 10 times & 0.2 & 1.3 & 1.6 & 4.1 \\
\hline 11) 11 times & 0.0 & 0.5 & 0.0 & 0.0 \\
\hline 12) 12 times & 0.0 & 0.5 & 0.0 & 0.0 \\
\hline Mean & 0.47 & 1.35 & 1.90 & 3.09 \\
\hline \multicolumn{5}{|l|}{ Complaintsł } \\
\hline 0) Never & 95.7 & 90.0 & 82.1 & 75.0 \\
\hline 1) Once & 2.5 & 3.1 & 5.5 & 7.6 \\
\hline 2) Twice & 0.7 & 3.0 & 5.5 & 6.9 \\
\hline 3) 3 times & 0.8 & 0.8 & 2.6 & 2.1 \\
\hline 3) 4 times & 0.3 & 1.0 & 1.7 & 3.5 \\
\hline 4) 5 times & 0.0 & 0.8 & 0.5 & 1.3 \\
\hline 4) 6 times & 0.0 & 1.0 & 1.6 & 3.0 \\
\hline 4) 7 times & 0.0 & 0.2 & 0.0 & 0.3 \\
\hline 4) 8 times & 0.0 & 0.0 & 0.2 & 0.2 \\
\hline 4) 9 times & 0.0 & 0.2 & 0.2 & 0.2 \\
\hline Mean (raw) & 0.08 & 0.28 & 0.46 & 0.71 \\
\hline Mean (collapsed) & 0.07 & 0.23 & 0.39 & 0.58 \\
\hline \multicolumn{5}{|l|}{ Trouble $\S$} \\
\hline 0) Never & 97.4 & 91.5 & 83.8 & 75.3 \\
\hline 1) Once & 1.5 & 4.1 & 7.8 & 11.3 \\
\hline 2) Twice & 1.0 & 2.5 & 4.3 & 4.7 \\
\hline 3) 3 times & 0.2 & 1.0 & 2.2 & 3.3 \\
\hline 3) 4 times & 0.0 & 0.2 & 0.9 & 1.3 \\
\hline 4) 5 times & 0.0 & 0.2 & 0.3 & 1.8 \\
\hline 4) 6 times & 0.0 & 0.3 & 0.3 & 1.5 \\
\hline 4) 7 times & 0.0 & 0.3 & 0.0 & 0.5 \\
\hline 4) 8 times & 0.0 & 0.0 & 0.3 & 0.2 \\
\hline 4) 9 times & 0.0 & 0.0 & 0.0 & 0.2 \\
\hline Mean (raw) & 0.04 & 0.18 & 0.33 & 0.60 \\
\hline Mean (collapsed) & 0.04 & 0.16 & 0.30 & 0.51 \\
\hline
\end{tabular}

- Missing data not included in percentages (6th, $n=6-7$; 8 th, $n=3-5$; 10 th, $n$ = 34-37; 12th, $n=2-6$ ).

† Grade 12 Overindulgence skewness $=0.630$.

$\ddagger$ Grade 12 Complaints raw data skewness $=2.496$; index skewness $=1.891$. $\$$ Grade 12 Trouble raw data skewness $=2.941$; index skewness $=2.158$ 


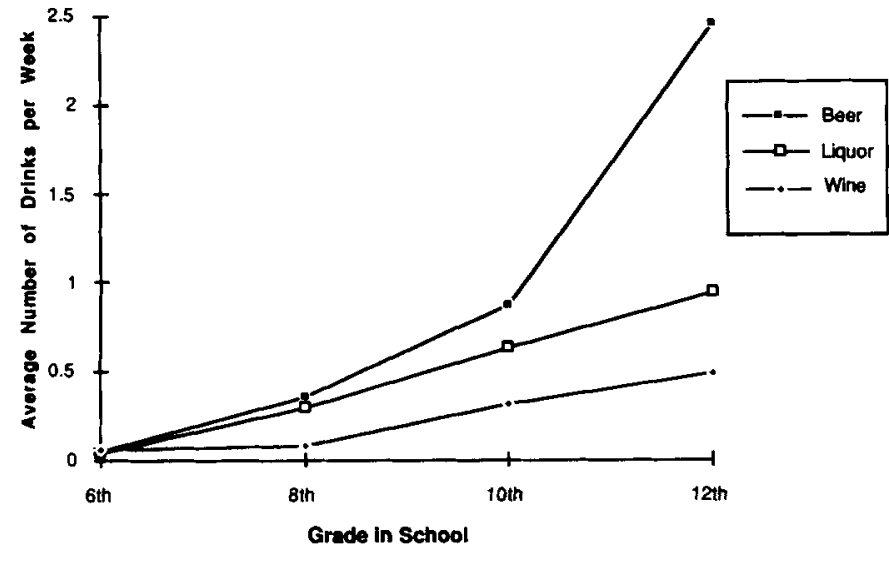

Fig. 1. Beer, liquor, and wine use in student cohort over time $(n=613$; missing data $=8-44)$.

dents reporting "none" from 6th to 12th grades is apparent, as are the increases in the higher levels of use categories. Overall, even at grade 12 , however, the majority of students reported drinking none or $<1$ drink/week.

The results of the newly categorized measure are reported in Table 2 under "revised measure." The revised measure included more categories at lower levels of use, and thus gives more specificity to the data in that range. The more even distribution of responses can be seen at all grade levels, with skewness a problem only at grade 6 .

\section{Alcohol Misuse}

Students' responses to the alcohol misuse items are reported in Table 3, which also shows the distributions on the initial three indices and total misuse index. Total misuse increased over time, from being very infrequent among 6 th grade students ( $76 \%$ reported no misuse) to fairly frequent among 12 th grade students (more than half reported at least two instances of alcohol misuse). Experience with the consequences of overindulgence, particularly, was reported by most of the 12 th grade students.

The percentages of students' responses falling into each coded category of the revised alcohol misuse indices are reported in Table 5. Overindulgence appears similar because the items remained the same, but the greater spread of scores is apparent. Complaints about their drinking were rarely experienced by students in the 6th grade, but experienced by $25 \%$ in the 12 th grade. Likewise, getting into trouble with others because of drinking had not been experienced by $97 \%$ of the 6th graders, but only $75 \%$ of the 12 th graders avoided this consequence.

\section{Correlations}

Correlations among the revised alcohol use and misuse measures at each data collection occasion are shown in Table 6. The correlations are positive, as expected, and for the most part are not so high as to argue for the combining of measures. The highest correlation is that between overindulgence and the alcohol frequency/quantity measure at grades 8,10 , and 12 . The items, however,
Table 6. Correlations Among Revised Alcohol Use and Misuse Measures within Each Grade Over Time*

\begin{tabular}{lccc}
\hline & Overindulgence & Complaints & Trouble \\
\hline Alcohol frequency/quantity & & & \\
Grade 6 & 0.54 & 0.30 & 0.17 \\
Grade 8 & 0.73 & 0.39 & 0.38 \\
Grade 10 & 0.78 & 0.42 & 0.41 \\
Grade 12 & 0.79 & 0.41 & 0.47 \\
Overindulgence & & & \\
Grade 6 & & 0.39 & 0.28 \\
Grade 8 & & 0.41 & 0.42 \\
Grade 10 & & 0.48 & 0.49 \\
Grade 12 & & 0.44 & 0.52 \\
Complaints & & & \\
Grade 6 & & & 0.32 \\
Grade 8 & & & 0.29 \\
Grade 10 & & & 0.32 \\
Grade 12 & & & 0.44 \\
\hline
\end{tabular}

- All correlations significant at $p<0.001$.

in those measures are quite dissimilar, supporting the need for separate measures. In general, the pattern of correlations offers support for the validity of the measures used.

\section{DISCUSSION}

In the context of evaluating a longitudinal school-based alcohol misuse prevention program, questionnaire items to assess adolescent alcohol use and misuse were chosen from the rather sparse literature available in the early 1980 s and adapted as necessary. Summary measures were initially developed from these items, taking into consideration the prevalence of alcohol use and misuse in the younger grades and what was expected in the older grades. Later, when students' data from the 12th grade were collected and examined, it was apparent that the initial measures did not adequately portray the alcohol consumption and misuse patterns of the older students, 60 $74 \%$ of whom were still drinking less than one drink/week in grades 12 and 10 , respectively. Revised response categories of the alcohol use measure were established to produce greater specificity and a more balanced distribution. The alcohol misuse item responses were factor-analyzed and revised indices were built. These revised alcohol use and misuse measures still utilized the item content appropriate for the younger grades, but provided the flexibility necessary to reflect the wide range of alcohol use and misuse among the students as they moved from grade 6 through grade 12, as evidenced in Tables 2 and 5 .

Further, the revised measures demonstrated desirable psychometric characteristics. The significant and positive correlations of the alcohol misuse indices with each other, as well as with the alcohol frequency/quantity measure attest to the construct validity of the measures. The revised alcohol use measure appears valid and reliable, resulting in data reports that show increased use over time, as expected in this age group, and that correlate with the other measures as expected. The alcohol use data have been categorized into a reasonably rectangular distribution (at least when the students are older) for analytic purposes. 
The revised measure also offers more specific data about the lower levels of drinking. This information is especially valuable because many students $(44.3 \%$ at grade 10 and $38.5 \%$ at grade 12 ) reported $<1$ drink/week on the initial measure. That category included those that drank as much as nearly 1 drink/week, as well as those that had as little as 1 drink in the whole previous year. The revised measure provides three more specific categories for the wide-ranging responses that were in one category in the initial measure but clearly represent different drinking patterns. Further, the revised measure's categories at the higher levels of drinking ( 3 to $<8$ and $>8$ drinks/week) are sufficiently high to be considered problematic for adolescents for whom alcohol consumption is illegal, unsafe, and an impediment to learning and development. When the initial measure was adopted. the study cohort was in elementary school and one could only speculate about their alcohol use in high school. After high school data were obtained, however, a more realistic measure for the alcohol use of adolescents could be developed.

The revised alcohol misuse factors/measures are both internally consistent and replicable. Data from those measures can be collapsed and recoded to reduce skewness for analytic purposes. Although it would not be inappropriate to continue using the misuse indices developed initially on an a priori basis, the opportunity to confirm or revise those indices based on factor analyses of older students with higher levels of reported misuse was too valuable to ignore. Although the items comprising the revised overindulgence index remained the same as in the a priori index, the other two indices changed in a slight, but significant way. Rather than the items separating based on their emphases on peers versus adults, the items separated based on their emphases on complaints from others versus getting into trouble with others. One could interpret the misuse measures as a sequence of events, as evidenced by their frequency of occurrence: overindulgence may occur first and most often; then adolescents may experience complaints about their drinking; and then they may experience trouble because of their drinking.

In terms of estimating the prevalence of alcohol consumption, the measure used has some limitations. As others have noted ${ }^{25}$ asking separate questions about beer, wine, and liquor consumption yielded more valid, specific information than general alcohol questions did. Yet such specific questions may not elicit reports of all alcohol use. When asked by students if the wine questionnaire item was meant to include wine coolers, project staff responded positively. Some students, however, may not have thought to ask, and others may have believed that wine coolers do not contain alcohol (as revealed in some of their comments to project staff). Several specific questions gather more precise information than a general question, but there are limitations on how many specific alcoholic drinks might be listed and asked about in a questionnaire.

The primary measures used in this study reflected a time frame of "the past year." Although such a long time span is associated with loss of precision, there is a gain in validity because of fluctuations in drinking patterns over a longer period of time. ${ }^{3}$ Little et al..$^{5}$ also concluded that the cost of retrospective measurement is higher when a very precise, rather than a more approximate, method of measurement is used. Furthermore, when used in a longitudinal study, such as the one reported herein, the pattern over time is readily noted. These summary measures are adequate for the purpose of longitudinal comparison in the evaluation of programs. When the goal is prevalence estimation, however, the degree of detail in asking questions would increase commensurate with the degree of precision desired.

Although for the purposes of measurement considerations the current report is adequate, caution should be used in extracting prevalence statistics for generalization from this report. The original study sample was representative only of the public school students in the semirural to suburban communities involved in the study. Also, as noted, attrition in the longitudinal data set led to significant 6th grade differences in ethnicity and alcohol use/ misuse between the longitudinal cohort and those with incomplete data. The students who were at school and completed the survey at each administration over the 6 years of follow-up initially drank less, reported fewer consequences of drinking, and were more likely to be White than the students who missed one or more of the followup surveys. It is not known how the lost-to-follow-up students would have reported alcohol use and misuse at the 12th grade data collection occasion. Of interest, however, is the finding that the mean number of alcoholic drinks/week reported in 12th grade by students in the study cohort did not differ significantly from that reported by all other 12 th grade students surveyed $(n=1268)$. In addition, the results confirm those of others who find alcohol use and misuse to increase markedly from grade 6 through grade 12 . In spite of the attrition differences, the 12th grade prevalence statistics for alcohol use in this cohort were very close to those reported by a national study of high school seniors the same year. ${ }^{26}$ In fact, in this cohort, the lifetime prevalence was $5.8 \%$ higher, annual prevalence was $1.5 \%$ higher, and past month prevalence was $0.5 \%$ higher than the national study. Attrition would be more problematic in the evaluation of a prevention program, as discussed elsewhere. ${ }^{27}$

The authors' experience with the revised measures shows them to be more valid and comprehensive than those used previously. They offer better opportunities to detect changes in the prevalence and patterns of adolescent alcohol use and misuse over time. Efforts to understand the onset of drinking, levels of drinking, and drinking problems among adolescents will be well-served to use measures that capture the full range of adolescent drinking behavior. Careful measures of alcohol use and misuse would also be helpful in the study of antecedents of 
adolescent alcohol use and misuse. Much effort is being expended to prevent adolescent use and misuse of alcohol. The evaluation of such interventions should use the best measures possible or the interpretation of the results may be misleading. A separate paper from this study reports the alcohol misuse prevention intervention results, using the revised measures among high school students. ${ }^{28}$

Several other implications for other studies can be drawn from the authors' experience with this study. Researchers should continue to assess the adequacy of their measures to reflect the full range of data obtained, and to adjust their measures accordingly. Detailed questions should be asked separately about consumption of various alcoholic drinks, such as beer, wine, wine coolers, and liquor. Measures of misuse, or negative consequences of drinking, should be factor-analyzed, especially at the higher grade levels, to enhance understanding of these outcomes. The measures developed in this study were reliable, valid, and are available for application in replication studies. The measure of alcohol use can be used across a variety of ages, whereas the best measure of misuse may depend on the age group being studied. The measures from this study and the approach utilized to assess the adequacy of the measures may be helpful to other studies.

\section{REFERENCES}

1. Cahalan D, Cisin IH: American drinking practices: Summary of findings from a national probability sample. II. Measurement of massed versus spaced drinking. Q J Stud Alcohol 29:642-656, 1968

2. Dawson DA, Archer L: Gender differences in alcohol consumption: Effects of measurement. Br J Addict 87:119-123, 1992

3. Dunham RG: Rethinking the measurement of drinking patterns. J Stud Alcohol 44:485-493, 1983

4. Lemmens P, Tan ES, Knibbe RA: Measuring quantity and frequency of drinking in a general population survey: A comparison of five indices. J Stud Alcohol 53:476-486, 1992

5. Little RE, Mandell W, Schultz FA: Consequences of retrospective measurement of alcohol consumption. J Stud Alcohol 38:1777-1780, 1977

6. Jessor R, Jessor SL: Adolescent development and the onset of drinking. A longitudinal study. J Stud Alcohol 36:27-51, 1975

7. Jessor R, Graves TD, Hanson RC, Jessor SL: Society, Personality, and Deviant Behavior: A Study of a Tri-Ethnic Community. New York, Holt, Rinehart \& Winston, 1968

8. Greenwald MA: Minimizing Alcohol Problems and Smoking: Final Report Year II. University of Pittsburgh, 1982

9. Rachal JV, Williams JR, Brehm ML, Cavanaugh E, Moore RP, Eckerman WC: A National Study of Adolescent Drinking Behavior, Attitudes and Correlates: Final Report. Rockville, MD, National Institute on Alcohol Abuse and Alcoholism, 1975

10. Bachman JG, Johnston LD, O'Malley PM: Smoking, drinking, and drug use among American high school students: Correlates and trends, 1975-1979. Am J Public Health 71:59-69, 1981

11. Botvin GJ, Baker E, Dusenbury L, Tortu S, Botvin EM: Preventing adolescent drug abuse through a multimodal cognitive-behavioral approach: Results of a 3-year study. J Consult Clin Psychol 58:437-446, 1990

12. Ellickson PL, Bell RM: Drug prevention in junior high: A multisite longitudinal test. Science (Mar. 16) 247:1299-1305, 1990

13. Hansen WB, Graham JW: Preventing alcohol, marijuana, and cigarette use among adolescents: Peer pressure resistance training versus establishing conservative norms. Prev Med 20:414-430, 1991

14. Pentz MA, Johnson A, Dwyer JH, MacKinnon DM, Hansen WB, Flay BR: A comprehensive community approach to adolescent drug abuse prevention: Effects on cardiovascular disease risk behaviors. Ann Med 21:219-222, 1989

15. Dielman TE, Shope JT, Butchart AT, Campanelli P: Prevention of adolescent alcohol misuse: An elementary school program. J Pediatr Psychol 11:259-282, 1986

16. Dielman TE, Shope JT, Campanelli PC, Butchart AT: Elementary school-based prevention of adolescent alcohol misuse. Pediatr Int J Adol Health 14:70-76, 1987

17. Campanelli PC, Dielman TE, Shope JT, Butchart AT, Renner DS: Pretest and treatment effects in an elementary school-based alcohol misuse prevention program. Health Educ Q 16:113-130, 1989

18. Dielman TE, Shope JT, Leech SL, Butchart AT: Differential effectiveness of an elementary school-based alcohol misuse prevention program. J School Health 59:255-263, 1989

19. Shope JT, Dielman TE, Butchart AT, Campanelli PC: An elementary school-based alcohol misuse prevention program: Follow-up evaluation. J Stud Alcohol 53:106-120, 1992

20. Campanelli PC, Dielman TE, Shope JT: Validity of adolescents' self-reports of alcohol use and misuse using a bogus pipeline procedure. Adolescence 22:7-22, 1987

21. Akers RL, Massey J, Clarke W, Lauer RM: Are self-reports of adolescent deviance valid? Biochemical measures, randomized response, and the bogus pipeline in smoking behavior. Soc Forces 62:234-251, 1983

22. Hansen WB, Malotte CK, Fielding JE: The bogus pipeline revisited: The use of the threat of detection as a means of increasing selfreports of tobacco use. J Appl Psychol 70:789-792, 1985

23. O'Malley PM: Cigarette smoking among high school seniors: Did the rate decline? Prev Med 13:421-426, 1983

24. Dielman TE, Campanelli PC, Shope JT, Butchart AT: Susceptibility to peer pressure, self-esteem, and health locus of control as correlates of adolescent substance abuse. Health Educ Q 14:207-221, 1987

25. Russell M, Welte JW, Barnes GM: Quantity-frequency measures of alcohol consumption: Beverage-specific vs. global questions. $\mathrm{Br} \mathrm{J}$ Addict 86:409-417, 1991

26. Johnston LD, O'Malley PM, Bachman JG: Smoking, Drinking, and Illicit Drug Use among American Secondary School Students, College Students, and Young Adults, 1975-1991 (NIH Publication No. 933480). Washington, D.C.: U.S. Government Printing Office, 1992

27. Hansen WB, Collins LM, Malotte CK, Johnson CA, Fielding JE: Attrition in prevention research. J Behav Med 8:261-275, 1985

28. Shope JT, Copeland LA, Maharg R, Dielman TE: The effectiveness of a high school alcohol misuse prevention program with and without a previous elementary school program. Submitted for publication, 1993 